\title{
Arranjo Produtivo Local de Moda Íntima de Nova Friburgo (RJ): perfil atual e perspectivas de desenvolvimento \\ Fernanda Cavalcante Rangel ${ }^{1}$ \\ Teófllo Henrique Pereira de Paula ${ }^{2}$
}

\section{RESUMO}

RANGEL, F. C. e DE PAUlA, T. H. P. Arranjo Produtivo Local de Moda Íntima de Nova Friburgo (RJ): perfil atual e perspectivas de desenvolvimento: $O$ presente trabalho realiza uma caracterização do Arranjo Produtivo Local (APL) de Moda Íntima de Nova Friburgo (RJ). Busca-se identificar suas principais vantagens competitivas, bem como possíveis entraves ao seu desenvolvimento. Para isso, foi realizada uma pesquisa de campo, a qual envolveu a aplicação de questionários e a realização de entrevistas. Os resultados evidenciam, por um lado, um considerável dinamismo que tem contribuído para a sustentação de taxas de lucro em curto prazo. Por outro, são observadas deficiências quanto à coordenação e à cooperação, que podem afetar a competitividade em longo prazo, colocando a necessidade do estabelecimento de políticas públicas e privadas que visem à consolidação do setor.

Palavras-chave: economia regional; Arranjo Produtivo Local; competitividade.

\begin{abstract}
RANGEL, F. C. e DE PAUlA, T. H. P. The Local Productive Arrangement of underwear in Nova Friburgo (RJ): current profile and prospects of development: This paper analyses the current situation of the Local Productive Arrangement of underwear in Nova Friburgo (RJ). The aim is to identify its main competitive advantages, as well as possible obstacles to its future development. For this, we performed a field study, which involved the use of questionnaires and interviews. In order to present the results, we used graphics and tables. On the one hand, the results show a considerable dynamism that has contributed to maintain profit rates in the short term, but on the other, we observed deficiencies in coordination and cooperation, which can affect the long-term competitiveness, placing the need of public and private policies in order to consolidate the sector.
\end{abstract}

Key words: regional economy; Local Productive Arrangement; competitiveness.

\section{INTRODUÇÃO}

O Arranjo Produtivo Local - APL de Moda Íntima, objeto do presente trabalho, localiza-se no Estado do Rio de Janeiro, sendo formado pelas cidades de Nova Friburgo, Duas Barras, Cordeiro, Macuco, Cantagalo e Bom Jardim. Aproximadamente, 1/4 da produção nacional de moda íntima é realizado dentro dos limites geográficos desses municípios, destacando-se a cidade de Nova Friburgo como o centro do arranjo. Além da expressividade do volume de produção no âmbito nacional, o setor constitui um dos pilares da economia local, justificando-se, assim, o esforço investigativo cujos resultados são apresentados ao longo deste texto. 
O trabalho tem como objetivo realizar uma caracterização do APL de Moda Íntima de Nova Friburgo - RJ no que se refere à sua estrutura produtiva, capacidade inovativa e governança. Particularmente, busca-se identificar as principais vantagens competitivas, bem como os possíveis entraves ao seu desenvolvimento em longo prazo. Para isso, foi realizada uma pesquisa de campo, a qual envolveu a aplicação de questionários e a realização de entrevistas junto a empresas e a alguns agentes-chave do setor.

Além desta introdução, o trabalho está dividido em quatro partes, a saber: no item I é apresentado o conceito de APL, bem como discutidos alguns dos principais elementos teóricos concernentes a esta abordagem; o item II tem como objetivo apresentar brevemente a evolução histórica da referida aglomeração produtiva, bem como seus principais elementos estruturantes no período recente; no III são explicitados e discutidos os resultados da pesquisa de campo, seguindo-se, no item IV, de uma análise sobre as perspectivas do setor, com algumas proposições de política econômica. Finalmente, algumas considerações a título de conclusão são tecidas no item V.

\section{I - Arranjos Produtivos Locais (APLs)}

O conceito de APL pode, em linhas gerais, ser entendido como uma junção entre a Teoria dos Polos de Crescimento e elementos teóricos da escola neo-schumpeteriana (ou evolucionista, numa perspectiva mais ampla), agregando ainda contribuições da escola institucionalista (WILLIAMSON, 1985; NORTH, 1990; HODGSON, 2006), com aplicações bastante apropriadas para o estudo de aglomerações produtivas em países em desenvolvimento. Particularmente, Perroux (1977) atesta que o desenvolvimento não ocorre de forma homogênea no espaço, mas sim a partir de polos de crescimento. Na sua teoria, ganha destaque o papel exercido pela indústria motriz, aquela que, em função dos fortes encadeamentos para frente e para trás determina a dinâmica do crescimento econômico em uma dada região. Por sua vez, a escola neo-schumpeteriana, consubstanciada particularmente no trabalho de Nelson e Winter (1982), fornece a base teórica que confere à capacidade inovativa da firma o fator-chave para o sucesso no ambiente concorrencial. Tem-se, assim, um arcabouço teórico em que as questões que envolvem a inovação tecnológica extrapolam os limites da firma, passando a constituir elemento-chave para o entendimento dos processos de desenvolvimento econômico regional. Neste caso, a ênfase desloca-se da concorrência entre firmas para a concorrência entre regiões, a qual é levada a cabo por meio das aglomerações produtivas, isto é, dos APLs.

Não obstante, a inovação tecnológica não pode ser tratada de forma estanque ou desvinculada do ambiente em que a firma atua. Esta última se encontra envolvida por um aparato institucional de regras, codificadas ou não, que limita suas ações e disponibiliza possibilidades. Um APL refere-se, assim, a um aglomerado produtivo em que a ênfase está na análise das interações que conduzem à introdução de novos produtos e processos. Neste sentido, há a necessidade de uma conceituação ampla e dinâmica que inclua todas as redes de conhecimento, atores e instituições das quais a firma faz parte e que têm implicações sobre a introdução de inovações. Uma organização produtiva além das relações diretas com seus concorrentes, funcionários, fornecedores e consumidores deve interagir com inúmeros agentes, tais como governo, laboratórios de pesquisa, universidades, ONGs, firmas de outros setores e agentes financeiros. Portanto, ao se considerar que as atividades de cada um desses agentes envolvem novas redes de conhecimento e atores, tem-se como resultado um sistema de elevada complexidade, onde se verifica uma interdependência na busca de soluções. Por este motivo, abordagens estritamente setoriais, frequentemente utilizadas na análise de 
aglomerados em países desenvolvidos, mostram-se deficientes. Como pontuado por Cassiolato e Lastres (2001, p.40):

"Apesar de que a espacialidade e a cooperação sejam explicitadas em tal abordagem [setorial], ela utiliza uma visão simplificada de 'mudança tecnológica', entendida como sendo apenas o resultado de aquisição e uso de equipamentos (bens de capital). Coloca a 'difusão' de tecnologia como o principal processo de contribuição para a mudança tecnológica dentro do aglomerado e demonstra um interesse limitado sobre a dinâmica de criação e acumulação de capacitações internas ao aglomerado para gerar inovações”.

As implicações do ambiente macroeconômico nacional e internacional sobre as aglomerações são de extrema importância. Países periféricos geralmente apresentam instabilidades institucionais (mudanças de regras, de regulação de mercados de câmbio e financeiros, ajustes de preços) que corroem os pilares necessários ao estabelecimento de canais de relacionamento confiáveis e estancam o desenvolvimento de relações cooperativas sistêmicas entre os agentes econômicos.

Segundo Santos et al. (2002), um ambiente não-cooperativo emerge deste contexto, com efeitos deletérios sobre a especialização produtiva, divisão do trabalho e produtividade, dificultando o estabelecimento de canais de aprendizado coletivo e colocando em risco o desenvolvimento da aglomeração como um todo.

Para países em desenvolvimento, parece mais apropriado tentar entender os mecanismos que possam conduzir à transformação de aglomerados geográficos em APLs. Faz-se assim, necessário, entender o processo de coordenação que rege as mais variadas relações verificadas em uma atividade produtiva, isto é, a governança. O modo como se procederá a governança de um APL dependerá do tipo de aglomeração produtiva considerada.

Para que um aglomerado de empresas possa ser considerado um APL, um determinado número de condições deve ser atendido, tais como: presença de número significativo de empresas e demais agentes especializados em uma determinada atividade produtiva; existência de mão-de-obra local qualificada; existência de atividades correlacionadas "para frente" e "para trás" da cadeia produtiva, com forte interdependência entre as empresas e demais agentes; articulação do sistema local com o exterior; presença de instituições locais comunitárias e públicas capazes de compreender e sustentar o sistema e de promover seu desenvolvimento, favorecendo a inovação, a cooperação, a solidariedade e a reciprocidade (CASSIOLATO \& LASTRES, 2001, p. 47).

Os casos em que o sistema de governança vigente não logra, por si só, a consolidação das características acima descritas, com a emergência de padrões eficientes de cooperação e de aproveitamento de externalidades decorrentes da atuação em rede, constitui um campo onde se faz necessária a implementação deliberada de políticas pública e privada.

\section{II - O APL de Moda Íntima de Nova Friburgo - RJ: evolução histórica e elementos estruturantes}

Este item faz uma caracterização geral do objeto de estudo, destacando elementos históricos e estruturais. Para tanto, foi realizada uma breve revisão de literatura sobre o APL em questão, agregando-se informações obtidas em entrevistas realizadas junto a atores-chave do arranjo, a saber: SEBRAE, FIRJAN, Sindicato das Indústrias do Vestuário (SINDVEST), Banco do Brasil 
(Agência Nova Friburgo - RJ), Conselho de Moda, Caixa Econômica Federal (Agência Nova Friburgo - RJ) e Secretaria de Ciência e Tecnologia de Nova Friburgo.

Dentre os municípios que compõem o APL, Nova Friburgo destaca-se não apenas por reunir o maior número de empresas, mas também por sediar as empresas líderes (La ROVERE, 2000). Sua população é de aproximadamente 170 mil habitantes e encontra-se localizado na região centronorte do Estado do Rio de Janeiro. Além das atividades ligadas à indústria têxtil e de confecções, no município destacam-se também a indústria metal-mecânica e de cimento, bem como o agronegócio e o turismo. O setor têxtil e de confecções é composto basicamente por micro e pequenas empresas, com ênfase em confecção de moda íntima. De acordo com Lemos, Albagli \& Szapiro (2004), no ano de 2004, Nova Friburgo produziu aproximadamente 350 milhões de peças, com um faturamento da ordem de R \$2,5 bilhões. Não obstante, apenas pouco mais de $2 \%$ da produção do município, nesse segmento, eram destinados ao mercado externo.

Ainda segundo Lemos, Albagli \& Szapiro (2004), havia 570 empresas formais no ano de 2004, sendo que as estimativas quanto ao número de empresas informais variavam de 300 a 1000 . Atualmente, só no sindicato patronal (SINDVEST), estão cadastradas 1500 empresas - considerando-se que nem todas as empresas formais estão cadastradas no SINDVEST, espera-se que esse número seja ainda maior. O elevado nível de informalidade é geralmente associado à inexistência de barreiras à entrada (confecções “fundo de quintal”) e à elevada carga tributária (RANGEL, 2010b e 2010c).

A indústria local de moda íntima foi impulsionada na década de 1980, a partir das demissões em massa da Filó S.A., empresa multinacional de grande porte, produtora de tecido de elastano e de lingerie. Como alternativa e valendo-se dos conhecimentos acumulados na produção, parte dos funcionários demitidos da Filó S. A. (costureiras, em sua maioria) constituiu micro e pequenas empresas dedicadas à confecção de lingerie. À época, a Filó desfez-se de mais de uma centena de suas máquinas, que foram arrendadas para os novos empreendedores.

No que se refere aos mercados, São Paulo constitui o principal destino da produção do APL, bem como cerca de $80 \%$ das matérias-primas são também provenientes deste estado. Por outro lado, a maioria dos equipamentos é importada. As vendas para o mercado interno são feitas através de canais variados: lojas próprias, encomenda de grandes varejistas e, principalmente, atravessadores e "sacoleiras", os quais respondem por cerca 70\% do escoamento da produção (LEMOS, ALBAGLI \& SZAPIRO, op. cit.).

O investimento em novas tecnologias é baixo. Somente as maiores empresas utilizam inovações como o CAD (Computer Aided Design) e CAM (Computer Aided Manufacturing), que são tecnologias introduzidas no APL pelo Instituto Politécnico da Universidade Estadual do Rio de Janeiro - UERJ, em Nova Friburgo. Essa tecnologia facilita o desenvolvimento de novos produtos e o melhor aproveitamento do tecido, evitando desperdício e aumentando a produtividade e a lucratividade da empresa. Além de caros para a realidade da maioria das empresas, estes equipamentos exigem mão-de-obra qualificada.

Um aspecto bastante particular do setor e que merece uma breve menção, refere-se às relações de subcontratação, também conhecidas como facções. Existem dois tipos de subcontratação, a saber: i) a subcontratação de pessoas; ii) a subcontratação de empresas. Os subcontratados geralmente recebem uma máquina cedida pela empresa e passam a fazer em casa o que fariam dentro da empresa. Apesar de pagar mais por unidade de produto, a facção revela-se uma estratégia lucrativa para a empresa na medida em que não implica encargos trabalhistas. Ademais, a produtividade aumenta 
porque as pessoas trabalham intensivamente, já que ganham por quantidade de produto, além de o empresário não ter o custo de manter funcionários quando as vendas diminuem. As empresas subcontratantes fornecem os insumos necessários às subcontratadas, as quais utilizam basicamente o seu trabalho. Depois de realizada a produção, as mercadorias são entregues à subcontratante, a qual realiza o controle de qualidade e a embalagem. Para a empresa subcontratada, esse tipo de relação é, a princípio, vantajosa, uma vez que não implica a necessidade de capital de giro. Esse recurso é frequentemente utilizado como uma estratégia que antecede a entrada da firma no mercado. Segundo Antônio José da Silva Neto, secretário municipal de Ciência e Tecnologia, a relação de subcontratação trará problemas sociais em longo prazo, pois os trabalhadores subcontratados ficam excluídos dos benefícios sociais, apesar de ganharem um pouco mais em curto prazo (RANGEL, 2010g).

Uma taxa de lucro relativamente elevada no setor é relatada pela maioria dos agentes entrevistados. Embora não se disponha de dados quantitativos que sustentem a afirmação, o significativo aumento do número de firmas nos últimos anos corrobora em alguma medida esta hipótese. Contribuem para este cenário a elevação da renda nacional e a expansão do mercado de moda íntima no período recente. No entanto, o aparecimento de novas regióes produtoras nos últimos anos como, por exemplo, a cidade de Muriaé/MG (VIVER BRASIL, 2011, p. 28) - pode evidenciar um ajustamento do setor no longo prazo. Com a entrada de novos ofertantes, atraídos por um lucro extranormal, o lucro tenderá a diminuir à medida que novas regiões produtoras se insiram no mercado. Esse fato reforça a ideia de que o tipo de concorrência que deve ser enfatizado é a concorrência entre regiões produtoras, isto é, entre APLs, e não entre as firmas do mesmo APL. A cooperação constitui-se, então, numa variável estratégica de sustentação da competitividade no longo prazo. A consciência da importância da cooperação começa a ganhar espaço entre os agentes do APL, como se pode observar pelos esforços empreendidos para a criação de uma marca do APL (RANGEL, 2010f).

\section{III - RESULTADOS DA PESQUISA DE CAMPO E DISCUSSÃO}

Esta seção apresenta e analisa as principais informações obtidas por meio da aplicação de questionário junto a 31 empresas sediadas em Nova Friburgo - RJ, entre os meses de janeiro e fevereiro de 2010. Para tanto, utilizou-se o questionário disponibilizado pela Rede de Pesquisa em Sistemas Produtivos e Inovativos Locais - REDESIST, do Instituto de Economia da UFRJ (REDESIST, 2003). As informações são apresentadas na forma de gráficos e tabelas.

\subsection{Configuração atual do APL}

A livre entrada, associada ao aumento da renda nacional e da área de mercado do APL nos últimos anos, aspectos já destacados nas seções anteriores, configura um ambiente bastante favorável para os empreendimentos locais no setor. Tal hipótese é corroborada por uma correlação positiva, calculada a partir da amostra entre o tempo de vida e o número de funcionários, que foi de 0,75 . Adicionalmente, a taxa de crescimento das empresas, medida pelo nível de emprego, também revelou-se bastante significativa: estas tinham, em média, no ano de 2010, 7,31 funcionários e 8,09 anos de existência, e um número médio de empregados no primeiro ano de vida de 2,52, o que resulta em um crescimento relativo médio de aproximadamente $23,5 \%$ ao ano. 
Todavia, o número de casos em que o processo de entrada e expansão converge para a formalização parece ainda distante do desejável. A partir da amostra, o grau de informalidade estimado é de $71 \%$. Quando questionados se gostariam de formalizar sua confecção, os empresários foram unânimes

ao afirmar que sim, porém, como mostra a Figura 1, os altos tributos foram apontados por 19 das 31 empresas pesquisadas como o principal entrave ao ingresso na economia formal.

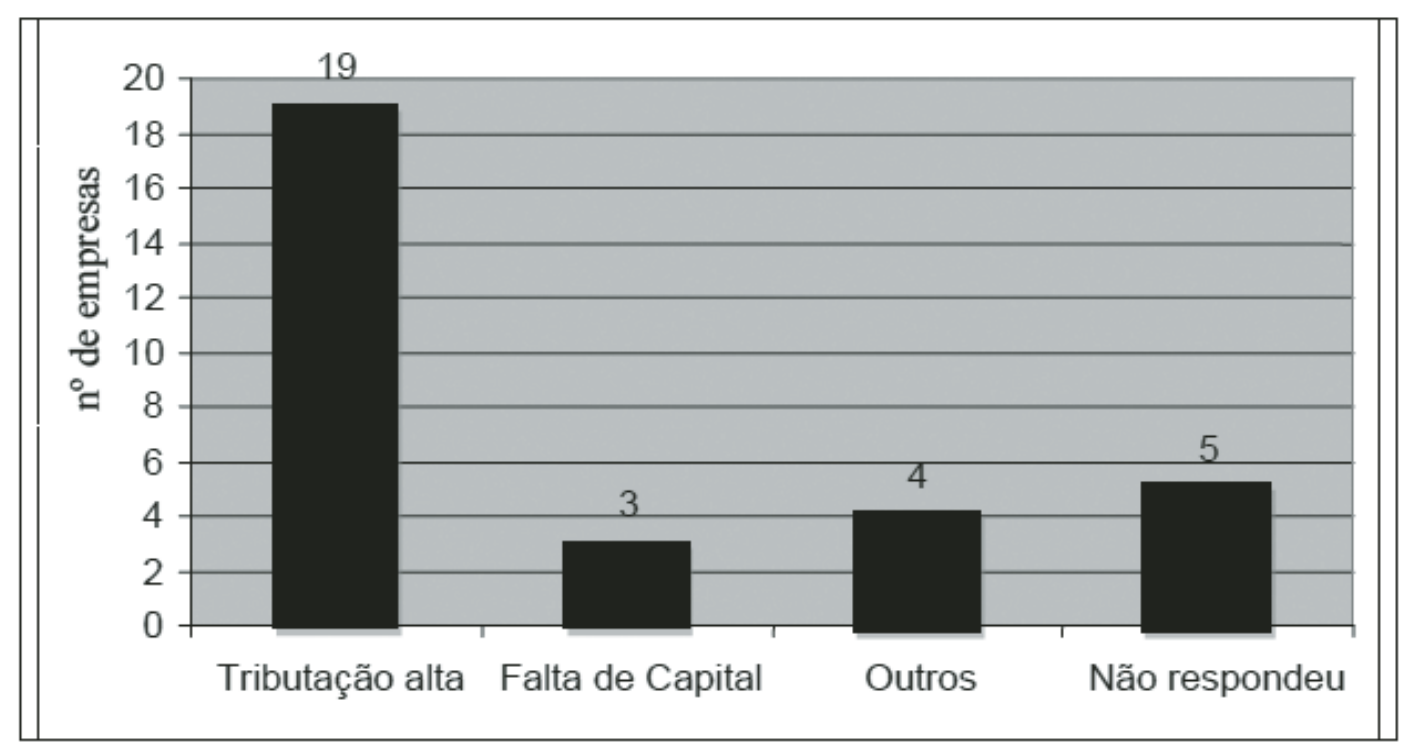

Fonte: Elaborado pelos autores com base em informações obtidas em pesquisa de campo.

Figura 1: Obstáculos à legalização ( $n^{\circ}$ de respostas)

No que se refere aos canais de distribuição da produção, 26 empresas responderam à questão. Como se observa na Figura 2, 11 empresas informaram que vendem a sua produção ao agente aqui denominado Distribuidor e outras 9 ao Distribuidor e a lojas, ao mesmo tempo. Aqui é possível atestar o papel-chave desempenhado por este agente (o Distribuidor) que, ao se deslocar no território em busca de novos mercados, configura-se como um dos principais responsáveis pela expansão da demanda observada no período recente.

Questionamentos envolvendo variáveis financeiras tiveram um baixo nível de respostas. Quando perguntados sobre o gasto mensal com fornecedores, apenas 16 empresários responderam. O gasto médio foi de $\mathrm{R} \$ 15.887,50$, com desvio padrão de $\mathrm{R} \$ 13.647,56$. O gasto mensal com funcionários apresentou média de $\mathrm{R} \$ 4.676,43$ e desvio padrão de $\mathrm{R} \$ 4.987,75$, sendo que apenas 14 empresários responderam a esta questão. O faturamento médio em 2009 foi de $\mathrm{R} \$ 26.600,00$, com desvio padrão de $\mathrm{R} \$ 19.217,18$, sendo que somente 5 empresários responderam a essa pergunta. 


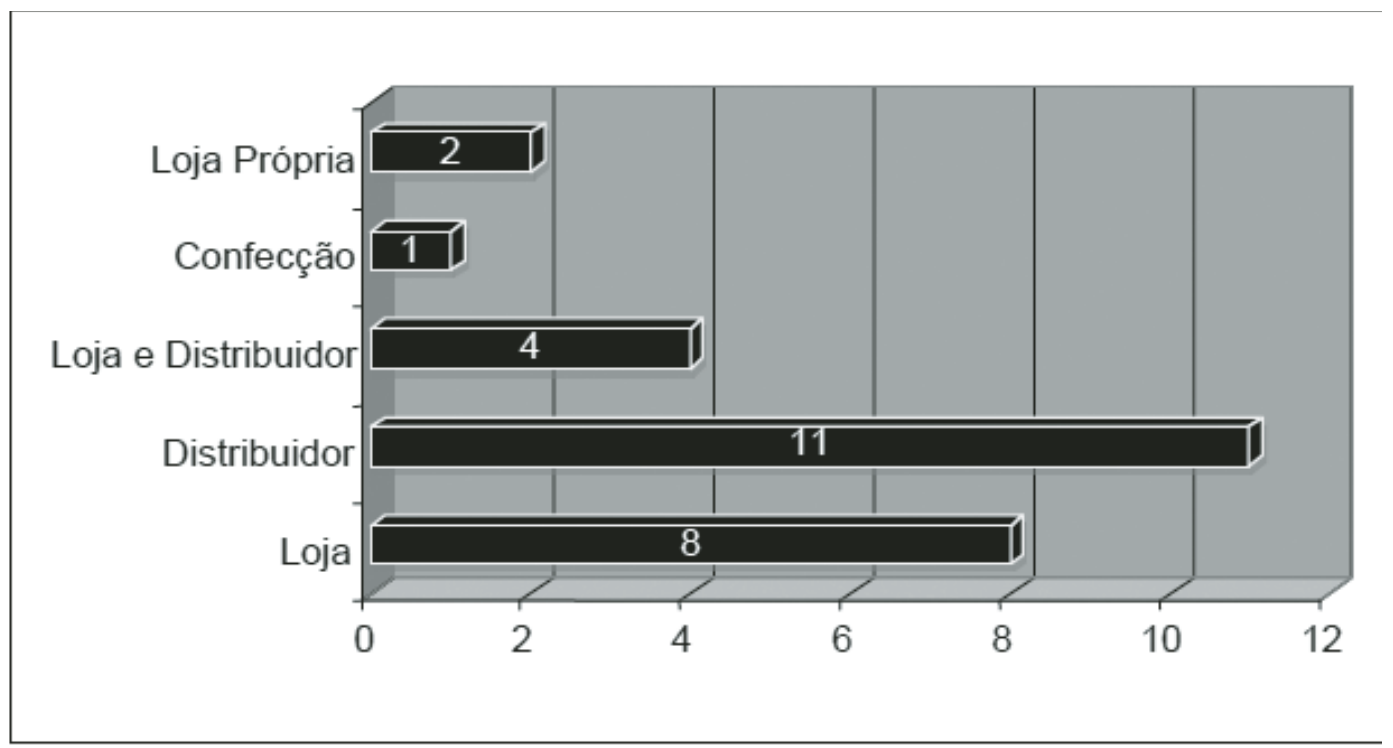

Fonte: Elaborado pelos autores com base em informações obtidas em pesquisa de campo.

Figura 2: Canais de distribuição da produção ( $\mathrm{n}^{\circ}$ de respostas)

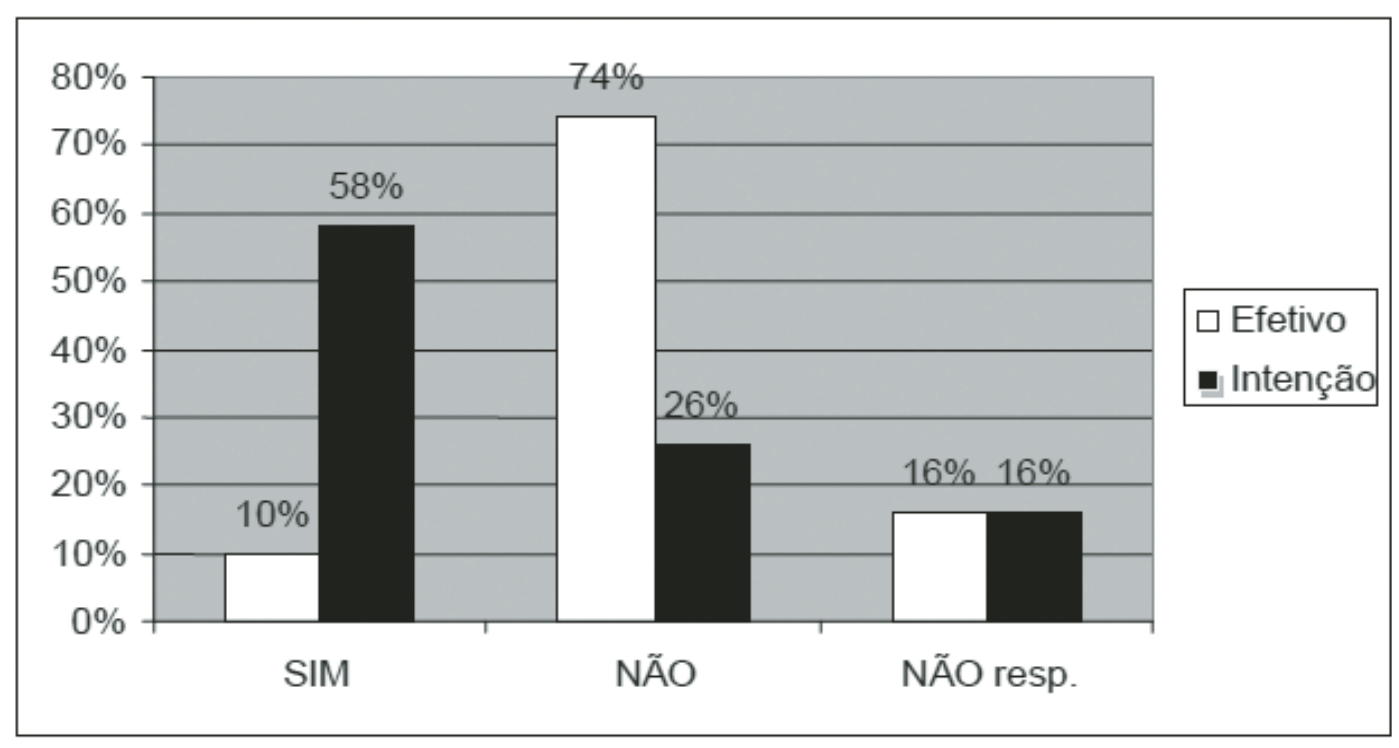

Fonte: Elaborado pelos autores com base em informações obtidas em pesquisa de campo.

Figura 3: Investimento em novas tecnologias ( $\mathrm{n}^{\circ}$ de respostas)

Na Figura 3, observa-se que 23 empresas (74\% da amostra) afirmaram não investir em nenhum tipo de melhoramento tecnológico. Não obstante, nota-se que existe a consciência sobre a importância das inovações, dado que 18 empresas (58\%) afirmaram que têm a intenção de realizar investimentos nesta área. Cinco empresas não responderam à questão. 
No que tange à estratégia competitiva, a diferenciação de produtos é feita basicamente a partir da utilização de novas matérias primas, como se observa na Tabela 1.

\begin{tabular}{lc}
\hline Matéria-prima nova & 9 \\
Moldes novos & 1 \\
Matéria-prima e bijuterias novas & 1 \\
Matéria-prima e moldes novos & 9 \\
Todas as alternativas anteriores & 1 \\
Não desenvolve & 4 \\
\hline
\end{tabular}

Fonte: Elaborado pelos autores com base em informações obtidas em pesquisa de campo.

Obs.: Total de respostas -25 .

Tabela 1: Estratégia para a diferenciação de produtos ( $\mathrm{n}^{\circ}$ de respostas)

O design dos produtos é, em sua maioria, desenvolvido pelos próprios empresários. Para a criação de um novo produto, além da criatividade do próprio empresário, são utilizadas revistas de moda e outros modelos observados nas lojas do APL e na televisão.

No que se refere à adesão sindical, o Sindicato das Indústrias do Vestuário - SINDVEST, apesar de contar com mais de 800 empresas sindicalizadas, não tem um alcance amplo, já que a maioria das empresas é informal; algumas nem mesmo sabem da existência do sindicato patronal. $O$ SINDVEST oferta cursos de capacitação para os empresários sindicalizados e outras empresas formais não sindicalizadas. Entretanto, como apurado a partir de entrevista realizada junto à presidência da entidade, o alcance é amplo apenas dentro de um grupo específico de empresas (RANGEL, 2010f). Das empresas pesquisadas, 15 revelaram a intenção de sindicalizar-se, contra 6 manifestando o oposto (10 empresários não responderam à questão). Os motivos alegados para a não adesão são basicamente a falta de contato $(15$ empresas $)$ e a ideia de que não traria benefícios (4 empresários).

As Tabelas 2, 3 e 4 apresentam a percepção de importância por parte dos empresários com respeito a alguns aspectos do APL. Inicialmente, a Tabela 2 revela o reconhecimento da proximidade geográfica como um fator de competitividade, tal como se depreende dos altos valores atribuídos às variáveis relacionadas à proximidade com fornecedores, clientes e fabricantes de equipamentos, bem como à disponibilidade local de mão-de-obra. Em consonância com este aspecto, as informações apresentadas na Tabela 3 evidenciam a importância das transações realizadas dentro do APL, ou em outros termos, a forte interdependência entre os fatores locais. Não obstante, a cooperação entre as empresas é pequena, o único tipo de cooperação citado é o empréstimo de matérias-primas e a troca de modelos novos entre as firmas. 


\begin{tabular}{lll}
\hline Itens & Média & Desv. Padrão \\
\hline Oferta de mão-de-obra qualificada & 2,34 & 1,08 \\
\hline Baixo custo da mão-de-obra & 1,48 & 1,12 \\
\hline Proximidade com fornecedores de insumos & 2,59 & 0,80 \\
\hline Proximidade com clientes/consumidores & 2,59 & 0,68 \\
\hline Infraestrutura física (energia, transporte, comunicação) & 2,48 & 0,78 \\
\hline Proximidade com produtores de equipamentos & 2,31 & 0,97 \\
\hline Disponibilidade de serviços técnicos especializados & 1,90 & 1,05 \\
\hline Existência de programas de apoio e promoção & 0,17 & 0,66 \\
\hline Proximidade com universidades e centros de pesquisa & 0,28 & 0,75 \\
\hline
\end{tabular}

Fonte: Elaborado pelos autores com base em informações obtidas em pesquisa de campo.

Obs.: 0 = nenhuma importância; 1 = pouca importância; 2 = média importância; 3 = muita importância.

Total de respostas: 29.

Tabela 2: Vantagens por estar no APL (média do grau de importância atribuído - escala de 0 a 3 )

\begin{tabular}{lcc}
\hline \multicolumn{1}{c}{ Itens } & Média & Desv. Padrão \\
\hline Aquisição de insumos & 2,83 & 0,59 \\
\hline Aquisição de equipamentos & 2,90 & 0,31 \\
\hline Aquisição de peças e componentes & 2,77 & 0,43 \\
\hline Aquisição de serviços (manutenção, marketing etc.) & 2,57 & 0,86 \\
\hline Vendas do produto & 2,84 & 0,37 \\
\hline
\end{tabular}

Fonte: Elaborado pelos autores com base em informações obtidas em pesquisa de campo.

Obs.: 0 = nenhuma importância; 1 = pouca importância; 2 = média importância; 3 = muita importância.

Total de respostas: 30 .

Tabela 3: Transações realizadas dentro do APL (média do grau de importância atribuído - escala de 0 a 3)

\begin{tabular}{ccc}
\hline Itens & Média & Desv. Padrão \\
\hline $1^{\circ}$ e $2^{\circ}$ grau completo & 0,79 & 1,01 \\
\hline Nível Superior completo & 0,69 & 1,11 \\
\hline Conhecimento prático/técnico na produção & 2,93 & 0,37 \\
\hline Disciplina & 2,79 & 0,68 \\
\hline Flexibilidade & 2,86 & 0,58 \\
\hline Criatividade & 2,86 & 0,58 \\
\hline Capacidade de aprender novas qualificações & 2,90 & 0,56 \\
\hline
\end{tabular}

Fonte: Elaborado pelos autores com base em informações obtidas em pesquisa de campo.

Obs.: 0 = nenhuma importância; 1 = pouca importância; 2 = média importância; 3 = muita importância.

Total de respostas: 29 .

Tabela 4: Perfil da mão-de-obra local (média do grau de importância atribuído - escala de 0 a 3)

No que se refere à qualificação da mão-de-obra, a Tabela 4 confirma o baixo nível de escolaridade dos trabalhadores do setor. De fato, o empregador qualifica o empregado como experiente considerando apenas aspectos práticos do ofício (habilidade com costura, principalmente). Não 
é atribuída importância significativa à qualificação intelectual; como se observa, ao item "nível superior completo" foi atribuído o menor grau de importância.

Com respeito aos programas institucionais para o desenvolvimento do setor, a grande maioria desconhece a existência ou conhece, mas não participa (Tabela 5). A entidade mais lembrada é o SENAI, o qual oferece cursos de capacitação profissional.

\begin{tabular}{cccc}
\hline Instituição & Não conhece & Conhece, mas não participa & Conhece e participa \\
\hline Gov. Federal & 26 & 1 & 1 \\
Gov. Estadual & 28 & 0 & 0 \\
Gov. Municipal & 29 & 1 & 0 \\
SEBRAE & 24 & 5 & 2 \\
SENAI & 6 & 9 & 5 \\
\hline
\end{tabular}

Fonte: Elaborado pelos autores com base em informações obtidas em pesquisa de campo.

Tabela 5: Programas para o desenvolvimento do APL ( $\mathrm{n}^{\circ}$ de respostas)

Condizente com as informações da Tabela 5, a Tabela 6 indica que a maioria considera insuficientes os elementos para a avaliação dos programas. Cabe notar que o SENAI, instituição reconhecida como mais próxima do setor, tem a sua atuação avaliada positivamente.

\begin{tabular}{cccc}
\hline Instituição & Positiva & Negativa & Sem elementos para avaliação \\
\hline Gov. Federal & 2 & 0 & 25 \\
Gov. Estadual & 0 & 0 & 27 \\
Gov. Municipal & 1 & 0 & 26 \\
SEBRAE & 5 & 1 & 20 \\
SENAI & 11 & 1 & 7 \\
\hline
\end{tabular}

Fonte: Elaborado pelos autores com base em informações obtidas em pesquisa de campo.

Tabela 6: Avaliação dos programas(n ${ }^{\circ}$ de respostas)

Historicamente, nota-se no APL a pouca utilização do crédito bancário. Dentre as empresas pesquisadas, a grande maioria não recorreu a este instrumento no início do empreendimento. Particularmente, para 94\% o capital inicial originou-se de recursos próprios. A informalidade impede o acesso a taxas de juros mais baixas, o que, associado a uma lucratividade relativamente elevada, induzindo à utilização de recursos próprios, explica a reduzida demanda por crédito.

A Tabela 7 informa que o acesso restrito a mecanismos formais de financiamento é explicado basicamente por entraves burocráticos e fiscais, bem como pela condição de informalidade da maioria das firmas. Das empresas pesquisadas, 29 iniciaram suas atividades com capital próprio e apenas duas com a utilização de financiamento, a despeito da existência de uma linha de crédito específica para o segmento local. 


\begin{tabular}{ccc}
\hline Itens & Média & Desv. Padrão \\
\hline $\begin{array}{c}\text { Inexistência de linhas de crédito adequadas às necessidades } \\
\text { da empresa }\end{array}$ & 2,00 & 1,15 \\
$\begin{array}{c}\text { Dificuldades ou entraves burocráticos para utilizar as fontes } \\
\text { de financiamento existentes }\end{array}$ & 2,23 & 1,09 \\
$\begin{array}{c}\text { Exigência de aval/garantias por parte das instituições } \\
\text { financeiras }\end{array}$ & 1,93 & 1,27 \\
$\begin{array}{c}\text { Entraves fiscais que impedem o acesso às fontes oficiais de } \\
\text { financiamento } \\
\text { Informalidade }\end{array}$ & 2,31 & 1,18 \\
\hline
\end{tabular}

Fonte: Elaborado pelos autores com base em informações obtidas em pesquisa de campo.

Obs.: 0 = nenhuma importância; 1 = pouca importância; 2 = média importância; 3 = muita importância. Total de respostas: 16 .

Tabela 7: Impedimentos ao acesso a mecanismos formais de financiamento (média do grau de importância atribuído - escala de 0 a 3 )

Em linhas gerais, é possível afirmar que não existe uma percepção de que o setor pode ser dinamizado a partir de políticas públicas. Quando se consideram as informações da Tabela 5, que revelam um elevado desconhecimento (por falta de informação ou por inexistência) dos programas institucionais para o APL, é possível concluir que, de fato, a interação entre atividades produtivas e atividades de planejamento e coordenação é bastante deficiente ou, em outros termos, é uma realidade ainda distante para o setor.

\subsection{Uma comparação entre as empresas formais e informais}

Das 31 empresas que responderam ao questionário, 9 são formais e 22 são informais, o que permite realizar algumas comparações entre as duas categorias.

1. Inicialmente, os dados apresentados na Tabela 8 revelam que entre as empresas informais, as relações de subcontratação (facção) estão presentes em 36\% dos casos, contra $22 \%$ das formais. Como destacado anteriormente, tais relaçôes envolvem uma série de precariedades, uma vez que a atividade é desenvolvida à margem da legislação trabalhista e dos programas de seguridade social. Ainda segundo a Tabela 8, o nível de escolaridade dos empresários é mais elevado nas empresas formais, nas quais $44 \%$ dos empresários têm Ensino Médio completo ou mais, contra 14\% das informais. Provavelmente, associado a este fato, a falta de qualificação da mão-de-obra constitui um problema maior para os primeiros ao passo que, para os últimos, problemas relacionados ao custo ou falta de capital aparecem como mais relevantes (Tabela 9).

\begin{tabular}{lll}
\hline Itens & Formais & Informais \\
\hline Existência de relação de subcontratação & $22 \%$ & $36 \%$ \\
\hline Escolaridade maior ou igual a "Ensino Médio completo" & $44 \%$ & $14 \%$ \\
\hline
\end{tabular}

Fonte: Elaborado pelos autores com base em informações obtidas em pesquisa de campo. 


\begin{tabular}{ccc}
\hline Itens & Formais & Informais \\
\hline Contratar empregados qualificados & 2.11 & 1.18 \\
Produzir com qualidade & 0.78 & 0.86 \\
Vender a produção & 0.89 & 1.00 \\
Custo ou falta de capital de giro & 1.00 & 1.32 \\
Custo ou falta de capital para aquisição de equipamentos & 0.56 & 0.91 \\
Custo ou falta de capital para aquisição/locação de instalações & 0.33 & 0.64 \\
\hline
\end{tabular}

Fonte: Elaborado pelos autores com base em informações obtidas em pesquisa de campo.

Obs.: 0 = nenhuma importância; 1 = pouca importância; 2 = média importância; 3 = muita importância.

Tabela 9: Problemas enfrentados pelas empresas em 2009 (média do grau de importância atribuído - escala de 0 a 3)

Observa-se na Tabela 10 que o capital de giro médio é maior para as empresas formais. Entretanto, uma elevada dispersão para ambas pode ser um indicativo de que o tamanho da firma não constitui uma condição necessária para o ingresso na economia formal.

\begin{tabular}{ccc}
\hline Categoria & Média & Desv. Padrão \\
Formal & 76429,00 & 56917.70 \\
Informal & 13667,00 & 10661.50 \\
\hline
\end{tabular}

Fonte: Elaborado pelos autores com base em informações obtidas em pesquisa de campo.

Tabela 10: Capital de giro por categoria $(\mathbf{R} \$)$

Uma análise dos canais de distribuição utilizados por cada categoria revela que, neste quesito, as empresas formais baseiam-se majoritariamente em lojas no APL ( $44 \%$ contra $23 \%$ das informais). Por outro lado, as informais se utilizam em sua maioria dos chamados "distribuidores" (45\% contra $11 \%$ das formais). No primeiro caso, pode-se dizer que o demandante vai até o ofertante. Particularmente, este é um indício de que a marca em questão encontra-se relativamente consolidada. No segundo caso, o ofertante vai até o demandante por meio do Distribuidor. Este fato, juntamente com as informações contidas na Tabela 11, a qual indica níveis de preços mais elevados para as empresas formais, permite afirmar que estas tendem a priorizar a concorrência via diferenciação de produto, enquanto as informais tendem a competir via preço. Este argumento é ainda reforçado pelas informações apresentadas na Tabela 11, a qual indica uma discrepância significativa no que se refere a investimentos em tecnologia e em treinamento da mão-de-obra para o desenvolvimento de novos modelos.

Os dados revelam, ainda, que $41 \%$ das empresas informais atestaram não realizar qualquer atividade relacionada ao desenvolvimento de novos modelos, enquanto todas as empresas formais desenvolvem alguma atividade neste quesito. 


\begin{tabular}{ccc}
\hline Itens & Formais & Informais \\
\hline Investimento em tecnologia & $56 \%$ & $9 \%$ \\
Investimento em treinamento em design & $67 \%$ & $0 \%$ \\
\hline
\end{tabular}

Fonte: Elaborado pelos autores com base em informações obtidas em pesquisa de campo.

Tabela 11: Investimentos em tecnologia e treinamento

Uma comparação entre as tabelas 9 e 12, no que se refere à qualificação da mão-de-obra, sugere algumas diferenças importantes entre as duas categorias de firmas. Enquanto na primeira tabela as empresas formais atestaram a dificuldade de contratação de mão-de-obra especializada como um dos principais problemas enfrentados em 2009 (contrastando com as informais), a Tabela 12 indica que estas não consideram a disponibilidade de mão-de-obra qualificada como uma grande vantagem de se estar situada no APL (novamente, contrastando com as empresas informais). Embora não se disponha de informações suficientes para inferências mais precisas, uma explicação possível é de que as atividades desenvolvidas nas empresas formais apresentam um maior grau de complexidade - com a utilização de equipamentos e matérias-primas de maior conteúdo tecnológico, por exemplo - exigindo habilidades acima do nível médio observado na mão-de-obra local. Se, de fato, as atividades desenvolvidas nas empresas informais são menos complexas, a mão-de-obra local atende às necessidades destas e, consequentemente, isto se reflete na pouca importância atribuída a este quesito pelas firmas informais. Neste mesmo sentido, a pouca importância atribuída pelas empresas formais aos itens "disponibilidade de serviços técnicos especializados" e "proximidade com produtores de equipamentos", como sendo uma vantagem por estar no APL, indica uma maior dependência de serviços e produtos que não são ofertados localmente. É importante ressaltar que esta análise deve ser aprimorada por meio de informações mais específicas sobre a natureza das atividades desenvolvidas em cada tipo de empresa. Não obstante, sinalizam a necessidade de se considerar separadamente as duas categorias quando da elaboração e implementação de políticas de incentivo ao setor. 


\begin{tabular}{ccccc}
\hline Itens & \multicolumn{2}{c}{ Formais } & \multicolumn{2}{c}{ Informais } \\
& Média & Desv. Padrão & Média & Desv. Padrão \\
\hline Oferta de mão-de-obra qualificada & 1.75 & 1.49 & 2.57 & 0.81 \\
Baixo custo da mão-de-obra & 1.50 & 1.31 & 1.48 & 1.08 \\
Proximidade com fornecedores de insumos & 2.13 & 1.13 & 2.57 & 0.93 \\
$\begin{array}{c}\text { Proximidade com clientes/consumidores } \\
\text { Infraestrutura física (energia, transporte, }\end{array}$ & 2.13 & 0.99 & 2.76 & 0.44 \\
$\begin{array}{c}\text { comunicação) } \\
\text { Proximidade com produtores de equipamentos }\end{array}$ & 1.75 & 1.28 & 2.52 & 0.75 \\
$\begin{array}{c}\text { Disponibilidade de serviços técnicos } \\
\text { especializados }\end{array}$ & 1.25 & 1.04 & 2.14 & 0.96 \\
$\begin{array}{c}\text { Existência de programas de apoio e promoção } \\
\text { Proximidade com universidades e centros de }\end{array}$ & 0.38 & 1.06 & 0.00 & 0.00 \\
pesquisa & 0.13 & 0.35 & 0.24 & 0.77 \\
\hline
\end{tabular}

Fonte: Elaborado pelos autores com base em informações obtidas em pesquisa de campo.

Obs.: 0 = nenhuma importância; 1 = pouca importância; 2 = média importância; $3=$ muita importância.

Tabela 12: Vantagens por estar no APL (média do grau de importância atribuído - escala de 0 a 3)

Finalmente, cabe destacar que, assim como nas análises realizadas nos itens anteriores, a proximidade com universidades e a existência de programas de apoio permanece percebida como de pouca importância para ambas as categorias de empresa. De fato, deficiências na interação universidade-empresa é, reconhecidamente, um problema não só do APL em questão, mas da maioria dos setores industriais no Brasil.

\section{IV-Perspectivas do APL e diretrizes para a política econômica}

Em linhas gerais, as principais informações obtidas pela pesquisa referem-se à existência de um elevado nível de informalidade com implicações deletérias, particularmente, sobre a competitividade das firmas e sobre a qualidade do emprego no setor, bem como à ausência de uma percepção de coletividade, implicando um baixo nível de cooperação entre as firmas e demais agentes. A evolução recente do APL verifica-se num cenário de expansão da renda nacional e de aumento da concorrência - de produtos importados, notadamente da China (COSTA \& ROCHA, 2009) e de produtos de outras regiões do Brasil. Sem embargo, as informações levantadas permitem afirmar que, pelo menos no período analisado, os efeitos positivos do primeiro fato têm se sobressaído em relação aos efeitos negativos do segundo, no que se refere à expansão do setor.

Outro elemento relevante para a abordagem do problemasão ascaracterísticas específicas da atividade em questão, particularmente no que tange às reduzidas barreiras à entrada. A combinação de barreiras à entrada, praticamente inexistentes, com uma demanda em expansão é, inevitavelmente, a possibilidade de atuação de unidades produtivas que em outra situação não sobreviveriam. Estas unidades tendem a se caracterizar pela informalidade e pelo baixo investimento em inovações tecnológicas, o que propicia uma reduzida estrutura de custos, resultando numa competitividade 
espúria. Ademais, embora a atividade em questão seja bastante propícia para a diferenciação de produtos, tais firmas concorrem basicamente via preços, como ficou evidenciado na pesquisa.

É possível afirmar que existe uma preocupação ou uma consciência por parte do empresariado sobre a pertinência das questões relacionadas à inovação tecnológica. Entretanto, esta não se traduz em investimentos de fato neste quesito. Uma interpretação possível é de que o setor encontra-se, de certa forma, aprisionado (lock in) em uma condição subótima (ARTHUR, 1989), isto é, uma situação que se autorreforça, baseada em competitividade espúria, tal como descrito acima, associado à existência de uma desvantagem para a empresa que se move primeiro. Mais especificamente, a firma que isoladamente optar por se legalizar ou partir para uma concorrência via diferenciação, encontrar-se-á em desvantagem de custo em relação às demais. Assim sendo, há um incentivo à perpetuação da condição subótima, reforçada pelo predomínio de uma mentalidade "curtoprazista" no sentido de se explorar ao máximo todas as oportunidades de lucro enquanto a demanda se encontra em expansão. Nesta situação, a estrutura de governança deve contar com a participação ativa de um agente que desempenhe o papel de coordenar a evolução do setor, com ênfase numa perspectiva de longo prazo. Naturalmente, esta missão deve ser incentivada, senão capitaneada, pelo poder público local, tendo em vista a importância do setor para a economia regional.

Um dos grandes fatos estilizados em crescimento econômico é a sua natureza cíclica. Assim sendo, é possível afirmar que o APL de moda íntima de Nova Friburgo-RJ encontra-se numa situação de vulnerabilidade no que diz respeito à sustentabilidade da taxa de lucro e dos níveis de emprego e renda setorial, com efeitos sobre toda a economia local, num contexto de reversão cíclica. Tendo em vista o aumento da concorrência internacional e inter-regional, com a emergência do outros polos produtores, tal como destacado anteriormente, somente os setores mais bem organizados poderão seguir com resultados positivos num cenário de queda na demanda. O planejamento estratégico do setor deve ser tomado como uma prioridade pelo poder público local com vistas à manutenção do crescimento econômico e à estabilidade da economia regional. Como principal diretriz de política setorial local, destaca-se a criação de incentivos à legalização e à disseminação de informações sobre a pertinência de uma ação coordenada e sobre o foco da concorrência, a qual deve ser entendida como uma concorrência entre APLs e não entre firmas do mesmo APL. Ademais, é imprescindível que uma ênfase maior seja dada ao fator "qualidade do produto" ao invés do preço, tal como vem ocorrendo. Isto se faz relevante na medida em que a diferenciação de produtos implica uma curva de demanda mais inelástica o que, consequentemente, reduz a vulnerabilidade da firma e do setor como um todo.

Numa perspectiva de longo prazo, a competitividade pressupóe um elevado dinamismo inovativo que, por sua vez, não pode prescindir de um mecanismo de financiamento eficaz. Tais elementos não podem existir sem a inserção dos agentes produtivos na economia formal. A partir dos dados levantados, o que se verifica é que o financiamento das atividades ocorre basicamente com recursos próprios. A fragilidade deste mecanismo encontra-se no fato de que tais recursos nem sempre se encontram disponíveis de forma a permitir o aproveitamento das oportunidades que surgem no decorrer do processo concorrencial. Ademais, o risco é assumido integralmente pelo empresário, ao passo que poderia ser compartilhado com outros agentes, isto é, financeiros e produtivos, num contexto de ampliação da carteira de portfólio dos agentes financeiros junto ao setor. A taxa de lucro observada no setor é sem dúvida um atrativo para os bancos, entretanto, a condição de informalidade acaba por se constituir num obstáculo praticamente intransponível no que se refere ao estabelecimento de relações formais de financiamento. A demanda por crédito é também latente. O que ocorre, no entanto, é que a taxa de lucro relativamente elevada acaba desincentivando a firma 
a buscar o crédito bancário. Isto porque, a despeito dos problemas relacionados à utilização de recursos próprios, o empresário ainda continua preferindo esta via em vez de assumir os custos e incertezas implícitos no processo de legalização. Esse cenário permite atestar a existência de elevados Custos de Transação, cuja redução deve constituir uma prioridade para os planejadores públicos e privados relacionados ao setor, no sentido de se conduzir o APL ao grau de consolidação desejado.

\section{V - Considerações Finais}

O presente trabalho analisou o caso do APL de Moda Íntima da cidade de Nova Friburgo - RJ a partir de informações obtidas em pesquisa de campo. É possível afirmar que o bom desempenho das firmas do setor observado no período recente está relacionado basicamente com fatores externos, como o crescimento da renda nacional e a expansão sustentada do mercado específico de moda íntima. Não obstante, a consistência deste processo em longo prazo não está assegurada, basicamente em função do aumento da concorrência externa (à região), associada a deficiências quanto à atuação conjunta dos diversos atores do APL. A pesquisa evidenciou um elevado nível de informalidade - impedindo a utilização de mecanismos formais de financiamento -, um baixo nível de cooperação e uma baixa capacidade inovativa. É possível concluir, em linhas gerais, que a governança do APL deve ser fortalecida. Em casos como este, é imprescindível uma participação mais ativa das instituições públicas no sentido de incentivar e coordenar as ações conjuntas entre os diferentes atores. Dada a sua importância para a economia local, a consolidação do APL deve ser entendida como uma questão prioritária no que se refere ao bem-estar econômico regional.

\section{NOTAS}

${ }^{1}$ Bacharel em Ciências Econômicas pelo Instituto Três Rios da Universidade Federal Rural do Rio de Janeiro - ITR/ UFRRJ.

${ }^{2}$ Professor Adjunto do curso de Ciências Econômicas do Instituto Três Rios da Universidade Federal Rural do Rio de Janeiro - ITR/UFRRJ.

\section{REFERÊNCIAS}

ARTHUR, B. Competing Technologies, Increasing Returns, and Lock-In by Historical Events. Economic Journal. n. 99, 1989: 116-131.

CASSIOLATO, J. \& LASTRES, H. M. Aglomerações, cadeias e sistemas produtivos e de inovação. Cluster Revista Brasileira de Competitividade. Belo Horizonte, 2001: 38-48.

COSTA, A. C. R. \& ROCHA, E. R. P. Panorama da Cadeia Produtiva Têxtil e de Confecções e a Questão da Inovação. Rio de Janeiro: BNDES. 2009.

HODGSON, G.M. What are institutions? Journal of Economic Issues, vol. 40 n.1, 2006: 2-4. 
La ROVERE, R. L., HASENCLEVER, L., MELO, L. M., FIALHO, B. C. \& SILVA, M. M. Industrialização descentralizada: sistemas industriais locais - estudo do setor têxtil e de confecções. Arranjos e Sistemas Produtivos Locais e as Novas Políticas de Desenvolvimento Industrial e Tecnológico. Nota Técnica 37. Rio de Janeiro: IE/UFRRJ, 2000.

LEMOS, C., ALBAGLI, S. \& SZAPIRO, M. H. Promoção de arranjos produtivos locais: iniciativas em nível federal. Rio de Janeiro: IE/UFRJ, 2004.

NELSON, R. R., \& WINTER, S. G. An evolutionary theory of economic change. Cambridge, Mass.: Belknap Press of Harvard University Press, 1982.

NORTH, D. C. Institutions, Institutional Change, and Economic Performance. Cambridge: Cambridge University Press, 1990.

PERROUX, F. O Conceito de Pólo de Crescimento. In: SCHWARTZMAN, J. Economia Regional - Textos escolhidos. Belo Horizonte: CEDEPLAR/CETREDE - MINTER, 1977.

RANGEL, F. C. Entrevista com Renata Medeiros, Assessora de Projetos Setoriais do Sistema FIRJAN de Nova Friburgo. CD Rom. Três Rios (RJ): DCEEX/ITR/UFRRJ, 2010a.

Entrevista com Carolyne Gomes Jorge, SEBRAE de Nova Friburgo. CD Rom. Três Rios (RJ): DCEEX/ITR/UFRRJ, 2010b.

Entrevista com Nelci Loyola, presidente do Conselho de Moda. CD Rom. Três Rios (RJ): DCEEX/ITR/UFRRJ, 2010c.

Entrevista com Carlos Alberto Faneli Laurindo, Gerente Geral do Banco do Brasil de Nova Friburgo. CD Rom. Três Rios (RJ): DCEEX/ITR/UFRRJ, 2010d.

Entrevista com Michel de Oliveira Lessa, Gerente de Relacionamento da Caixa Econômica Federal de Nova Friburgo. CD Rom. Três Rios (RJ): DCEEX/ITR/UFRRJ, 2010e.

Entrevista com Carlos Eduardo Lima, presidente do SINDVEST. CD Rom. Três Rios (RJ): DCEEX/ITR/UFRRJ, $2010 \mathrm{f}$.

Entrevista com Antônio José da Silva Neto, Secretário de Ciência e Tecnologia de Nova Friburgo e professor do Instituto Politécnico da UERJ de Nova Friburgo. CD Rom. Três Rios (RJ): DCEEX/ITR/UFRRJ, 2010g.

Rede de Pesquisa em Sistemas Produtivos e Inovativos Locais - REDESIST. Questionário para Arranjos Produtivos Locais. Rio de Janeiro: IE/UFRJ. 2003.

SANTOS, F., CROCCO, M. \& LEMOS, M. B. Arranjos e sistemas produtivos locais em espaços industriais periféricos: estudo comparativo de dois casos brasileiros. Revista de Economia Contemporânea. Rio de Janeiro: IE/UFRRJ, 6(2), 2002: 147-180.

REVISTA VIVER BRASIL. Viver Minas: Zona da Mata. Goiânia: Viver Brasil, nº 4, 2011. 
RANGEL, F. C. et al.

WILLIAMSON, O. E. The Economic Institutions of Capitalism: Firms, Markets, Relational Contracting. New York: Free Press, 1985. 